\title{
Unexpected shifts in fatty acid composition in response to diet in a common littoral amphipod
}

\author{
R. J. McLeod ${ }^{1, *}$, G. A. Hyndes ${ }^{2}$, C. L. Hurd ${ }^{3}$, R. D. Frew ${ }^{1,4}$ \\ ${ }^{1}$ Department of Chemistry, University of Otago, PO Box 56, Dunedin, New Zealand \\ ${ }^{2}$ Centre for Marine Ecosystems Research, School of Natural Sciences, Edith Cowan University, 270 Joondalup Drive, \\ Joondalup, Western Australia, Australia \\ ${ }^{3}$ Department of Botany, University of Otago, PO Box 56, Dunedin, New Zealand \\ ${ }^{4}$ FAO/IAEA Division of Nuclear Techniques in Food and Agriculture, Wagramer Strasse 5, PO Box 100, 1400 Vienna, Austria
}

ABSTRACT: To determine whether fatty acid (FA) profiles are a useful biomarker to trace the flow of material in a coastal food web, we fed the sandhopper Bellorchestia quoyana specific seaweed diets, each with a contrasting FA profile including Durvillaea antarctica (Phaeophyta), Ecklonia radiata (Phaeophyta) or Ulva sp. (Chlorophyta). We then compared changes in FA composition in relation to diet for this sandhopper. After $12 \mathrm{~d}$, sandhoppers from each treatment had distinct FA profiles, particularly with respect to polyunsaturated FAs (PUFAs); however, increases in specific FAs did not relate to those FAs that were abundant in their diet. For example, sandhoppers fed PUFA-deficient Ulva sp. exhibited a relative increase in PUFAs. The E. radiata and Ulva sp. diets both caused significant shifts in sandhopper FA composition over the course of the experiment. In order to follow the assimilation of carbon and FAs, sandhoppers were fed natural or ${ }^{13} \mathrm{C}$-enhanced $E$. radiata or Ulva sp., and changes to the $\delta^{13} \mathrm{C}$ of individual FAs were measured over time. Turnover of the most

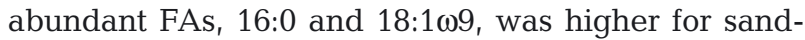
hoppers fed E. radiata than for those fed Ulva sp. Comparisons between bulk tissue $\delta^{13} \mathrm{C}$ and $\delta^{13} \mathrm{C}$ of individual FAs were consistent with sandhoppers modifying the turnover rate of FA in response to diet. These findings suggest that there is no consistent relationship between the FA compositions of green and brown seaweeds and that of the sandhopper B. quoyana. We caution that community-level application of FAs as a dietary biomarker tool must be accompanied by controlled experiments incorporating key species of relevance.

KEY WORDS: Stable isotopes · Biomarker · Food web · Seaweed · Invertebrate $\cdot{ }^{13} \mathrm{C}$ tracer $\cdot$ Compoundspecific stable isotopes · GC-IRMS

Resale or republication not permitted without written consent of the publisher

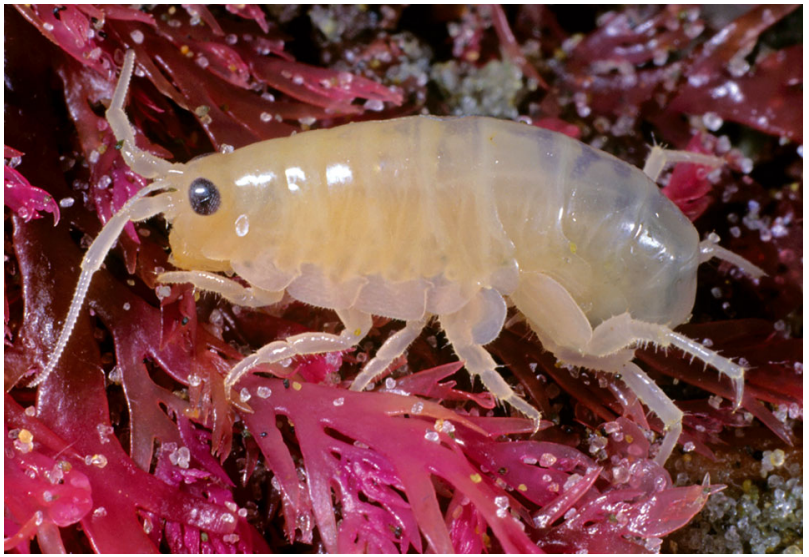

The talitrid amphipod Bellorchestia quoyana feeds on beach-stranded kelps and seaweeds.

Photo: @Rod Morris, www.rodmorris.co.nz

\section{INTRODUCTION}

Biomarker approaches are commonly used in food web studies to elucidate the specific roles of key primary producers in supporting secondary production (Dalsgaard et al. 2003, Fry 2006, Kelly \& Scheibling 2012). The development of such methods is particularly needed for coastal systems, where food webs are inherently complex due to the diversity and seasonality of autotrophs (Connolly et al. 2005, Wing et al. 2008, McLeod \& Wing 2009). These sources often include red, green and brown macroalgae, phytoplankton, terrestrial plants, seagrass and benthic 
diatoms. Analysis of carbon and nitrogen stable isotopes have arguably been the most popular chemical biomarker approach in marine food web studies to date (Layman et al. 2012); however, the approach can have limitations in coastal benthic settings, often including the overlap of isotopic signatures among autotrophs (Peterson 1999, Hanson et al. 2010) and variability in the fractionation of isotopic ratios during assimilation by consumers (McCutchan et al. 2003, Crawley et al. 2007, Caut et al. 2009). Many researchers have therefore incorporated complementary methods such as fatty acid (FA) trophic markers with their isotope studies (e.g. Alfaro et al. 2006, Guest et al. 2008, Tierney et al. 2008).

Whilst the use of FAs as dietary biomarkers has been extensively tested in pelagic, microalgal-based food webs (Graeve et al. 1994, 2005, Dalsgaard et al. 2003), there is a scarcity of experimental testing of FAs as markers for benthic food webs in natural (nonaquaculture) systems (Kelly \& Scheibling 2012). The foundation for an FA biomarker approach is that groups of primary producers possess unique or diagnostic FAs or ratios of FAs (Nelson et al. 2002b, Kelly $\&$ Scheibling 2012). Such diagnostic FAs have indeed been demonstrated for the different classes of marine phytoplankton fuelling open water food webs (Dalsgaard et al. 2003), such as the concentrations of 16:1 $1 \omega 7$ and $18: 4 \omega 3$ to discriminate between diatom and dinoflagellate diets (Graeve et al. 1994). Unfortunately, in coastal systems, many primary producers tend not to possess unique FAs (Dalsgaard et al. 2003, Kelly \& Scheibling 2012); however, different groups of primary producers can be distinguished by multivariate analysis of all FAs (Kelly \& Scheibling 2012). Using a multivariate approach, primary producers tend to group into green, brown or red macroalgae, diatoms and vascular plants (Crawley et al. 2009, Hanson et al. 2010, Kelly \& Scheibling 2012).

For FAs to provide appropriate dietary biomarkers, a specific FA or ratios of specific FAs must be transferred from food to consumer largely unaltered, thus indicating assimilation of specific dietary items (Auel et al. 2002, Bachok et al. 2003, Budge et al. 2008). Many invertebrates have the ability to biosynthesize FAs, thus having an overall FA composition that deviates from their diet (Dalsgaard et al. 2003, Bell \& Tocher 2009). For example, indications from aquaculture-based dietary studies are that when key FAs, such as essential longchain polyunsaturated FAs (PUFAs) are lacking from a diet, molluscs can biosynthesize these compounds from shorter-chain FAs (Uki et al. 1986), thus invalidating or at least complicating this assumption of unaltered trophic transfer of FAs.
An increasing number of feeding studies with freshwater and marine crustaceans are reporting bioconversion of $\mathrm{C}_{18}$ PUFAs to $\mathrm{C}_{20}$ and $\mathrm{C}_{22}$ PUFAs (e.g. Desvilettes et al. 1997, Schlechtriem et al. 2006, Caramujo et al. 2008). The recent development of gas chromatograph-isotope ratio mass spectrometry (GC-IRMS) analysis of stable isotope ratios of individual compounds, such as specific FAs, has provided a means to more closely examine FA turnover and biosynthesis (Boschker \& Middelburg 2002, Dalsgaard et al. 2003).

As a growing number of studies use FAs as biomarkers at a community level, it becomes increasingly important to improve our understanding of the effect of diet on FA profiles of a range of marine invertebrates. To date, only a few studies have examined the effects of natural diets on benthic invertebrates, focusing on abalone and sea urchins (Nelson et al. 2002a, Kelly et al. 2008, 2009). To provide the foundations for this approach in coastal systems, there is an urgent need for further tests of FA transfer between a range of sources and benthic consumers in controlled laboratory experiments.

Beaches are transitional habitats in terms of energy flux, with transfer of marine-sourced energy and organic matter such as beach-cast seaweeds into terrestrial food webs. Beach-cast seaweeds are grazed upon by invertebrates (Hyndes \& Lavery 2005, Ince et al. 2007, Mellbrand et al. 2011), which are in turn preyed upon by land-based birds and other vertebrates, resulting in the transfer of energy across coastal ecotones (Polis \& Hurd 1996). The amphipod Bellorchestia quoyana (family Talitridae), commonly referred to as a sandhopper, is a key component of New Zealand's beach food webs, with densities $>120000 \mathrm{~m}^{-2}$ occurring underneath beach-cast kelp (Marsden 1991a). The species composition of beachcast macroalgae on beaches in Otago is highly variable, both spatially and temporally, and tends to include material sourced from local reefs, and rafting species (e.g. Durvillaea spp. [Fucales] and Macrocystis pyrifera [Laminariales]; R. McLeod pers. obs.). M. pyrifera, Durvillaea spp., Ulva spp. and Ecklonia radiata are common to reef environments in southern New Zealand (Nelson 1994). Whilst B. quoyana tend to be most closely associated with $M$. pyrifera and $D$. antarctica in the natural environment (Marsden $1991 \mathrm{a}, \mathrm{b})$, they also consume a range of other seaweed species including E. radiata, Ulva spp. and Undaria pinnatifida (R. Suarez Jimenez unpubl. data). B. quoyana provides an excellent model organism for laboratory-based dietary studies, as it is fast-growing, short-lived (Marsden 1991b) and relatively easy to maintain in the laboratory. 
The first objective of this study was to determine whether the FA composition of Bellorchestia quoyana changes in response to specific macroalgal diets. We compared the response of $B$. quoyana to green versus brown macroalgae, as these 2 phyla of algae have very different FA profiles: green seaweeds typically have higher amounts of $\mathrm{C}_{16}$ and $\mathrm{C}_{18}$ PUFAs and lower amounts of long-chain PUFAs (including

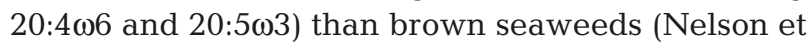
al. 2002b). We then examined the metabolic turnover of tissues and FAs of B. quoyana in response to diet by analysing stable isotope ratios of carbon $\left(\delta^{13} \mathrm{C}\right)$ in bulk tissues and individual FAs of seaweeds and $B$. quoyana. The addition of ${ }^{13} \mathrm{C}$ to diet, and subsequent tracing of the uptake of ${ }^{13} \mathrm{C}$ into specific FAs over time, facilitated this approach.

\section{MATERIALS AND METHODS}

\section{Expt 1: Does diet influence the FA and stable isotope composition of Bellorchestia quoyana?}

Bellorchestia quoyana (hereafter referred to as sandhoppers) were collected from Brighton Beach, Dunedin, New Zealand $\left(45^{\circ} 57^{\prime} 50.73^{\prime \prime} \mathrm{S}, 170^{\circ} 17^{\prime}\right.$ $\left.39.65^{\prime \prime} \mathrm{E}\right)$ and transferred to moistened oven-baked sand $\left(500^{\circ} \mathrm{C}, 5 \mathrm{~h}\right)$ for $24 \mathrm{~h}$ to allow gut contents to clear. Three sub-samples of 20 sandhoppers were collected at this point to provide an initial measurement of FA composition at the beginning of the experiment. Experimental containers $(\mathrm{n}=27,100 \mathrm{~mm}$ diameter, $200 \mathrm{~mm}$ height) were lined with ovenbaked sand (depth of $\sim 50 \mathrm{~mm}$ ) and were sprayed with a fine mist of sand-filtered seawater every $2 \mathrm{~d}$ throughout the experiment. Each container housed 20 sandhoppers (mixed sex and sizes ranging from 5 to $10 \mathrm{~mm}$ body length) and $\sim 6 \mathrm{~g}$ (blotted wet weight) of 1 of 3 seaweed diets (Ecklonia radiata, Durvillaea antarctica or Ulva sp.; $\mathrm{n}=9$ for each seaweed species). Samples of seaweed were collected from the drift line on Brighton Beach on the day of sandhopper collection. Replicates were arranged randomly, under the cover of clear plastic roofing panels (to protect from rainfall), outdoors in order to mimic natural conditions including light and temperature. Three replicate containers of each diet treatment were randomly selected and removed from the experiment on Days 1, 4 and 12. During this sampling, sandhoppers were transferred to clean sand for $12 \mathrm{~h}$ to allow gut clearance, then euthanased by freezing $\left(-20^{\circ} \mathrm{C}\right)$. Samples were then freeze-dried and ground with a mortar and pestle to an homogenous powder in preparation for chemical analyses. A minimum of 8 individuals was included in each sample for analysis. Autogenic controls $(n=4)$ were established for each seaweed diet and did not include sandhoppers. For these controls, the blotted wet mass of seaweed was measured at the beginning of the experiment and again on Day 12. To measure consumption rates by sandhoppers, the remaining seaweed in sandhoppercontaining replicates from Day 12 was picked from each jar, cleaned of sand, and the blotted wet weight was measured. Discrepancies in mass between the beginning of the experiment and Day 12 were determined and compared to autogenic controls.

\section{Expt 2: Does diet influence the turnover and biosynthesis of FAs in Bellorchestia quoyana?}

Ulva sp. and Ecklonia radiata were grown in ${ }^{13} \mathrm{C}$ enhanced seawater in order to artificially increase values of $\delta^{13} \mathrm{C}$. It was not possible to culture Durvillaea antarctica in aquaria due to constraints in the volume of seawater supplies in the laboratory (Kelly 1997). SCUBA divers collected individual Ulva sp. and juvenile E. radiata ( $200 \mathrm{~mm}$ length from holdfast to tip of blade) by hand from Karitane, Dunedin $\left(45^{\circ} 38^{\prime} 20.53^{\prime \prime} \mathrm{S}, 170^{\circ} 40^{\prime} 14.25^{\prime \prime} \mathrm{E}\right)$, and the samples were transported to the laboratory in coolers containing seawater. Individuals were weighted by the holdfasts and placed into individual 41 glass jars. Jars were arranged in a controlled temperature growth

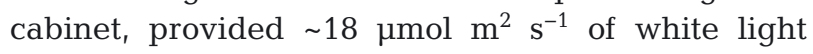
(white spectrum fluorescent tubes, Philips) and aerated by individual airstones. The medium included a base of filtered seawater $(3.5 \mathrm{l})$, with the addition of

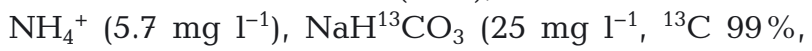
Cambridge Isotope Laboratories) and $\mathrm{NaH}_{2} \mathrm{PO}_{4} \cdot \mathrm{H}_{2} \mathrm{O}$ $\left(3.0 \mathrm{mg} \mathrm{l}^{-1}\right)$. Algae were cultured for a total of $7 \mathrm{~d}$. On Day 7, fresh specimens of Ulva sp. and E. radiata were collected from Karitane to provide unlabelled controls. Seaweeds were sliced into thin strips to provide a more isotopically homogenous sample for each replicate (due to ${ }^{13} \mathrm{C}$-uptake being heterogeneous within individual algae).

The experimental setup was the same as that described for Expt 1, with respect to collection and gut clearance of sandhoppers, mass of diets and housing and arrangement of the experiment. In this experiment, there were 6 sample treatments, consisting of either sandhoppers with ${ }^{13} \mathrm{C}$-labelled Ulva sp. or Ecklonia radiata, sandhoppers with unlabelled Ulva sp. or E. radiata, or Ulva sp. or E. radiata without sandhoppers (autogenic controls). Three replicate 
containers of each diet treatment were randomly selected and removed from the experiment on Days 1, 4, 12 and 17, and samples were treated as in Expt 1.

\section{Analysis of samples for FA composition}

Lipid was extracted from $\sim 10 \mathrm{mg}$ sub-samples of dried homogenized sandhoppers ( $\mathrm{n}=3$ per time/ treatment), and from $\sim 30 \mathrm{mg}$ sub-samples of dried homogenized macroalgae ( $\mathrm{n}=5$ where available) following Bligh \& Dyer (1959), as described previously (McLeod \& Wing 2007). A known quantity of nonadecanoic acid (19:0) was added to each sample to provide an internal quantitative standard. The lipid fraction was treated with boron trifluoride in methanol solution and underwent transesterification at $70^{\circ} \mathrm{C}$ for 20 min. FA methyl esters (FAMEs) were extracted in hexane/water, with the hexane-containing layer evaporated under nitrogen and then reconstituted and stored in dichloromethane at $-20^{\circ} \mathrm{C}$. Samples were then diluted with dichloromethane to obtain suitable concentrations for GC analysis.

FA composition was determined by GC on a 6850 GC System (Agilent Technologies) equipped with a flame ionization detector. FAMEs were separated on an Equity-1 capillary column $(15 \mathrm{~m} \times 0.10 \mathrm{~mm}$ i.d., $0.10 \mu \mathrm{m} \mathrm{film;}$ Supelco), with helium as the carrier gas (constant pressure of 4.25 bar). The column oven temperature began at $30^{\circ} \mathrm{C}$ for $3 \mathrm{~min}$, before being ramped to $270^{\circ} \mathrm{C}$ at $15^{\circ} \mathrm{C} \mathrm{min}^{-1}$ and then to $290^{\circ} \mathrm{C}$ at $5^{\circ} \mathrm{C} \mathrm{min}^{-1}$. FA peaks were identified by retention time matching with a range of specific FAs and confirmed using GC-MS. FAs were then expressed as the percentage of the total FAs and were also quantified gravimetrically with respect to the internal quantitative standard. Total FA concentration was used as an indicator of condition of composite samples of sandhoppers for each replicate.

\section{Bulk stable isotopes}

Sub-samples of $\sim 1 \mathrm{mg}$ of sandhoppers and $\sim 2 \mathrm{mg}$ of macroalgae were analysed for $\delta^{13} \mathrm{C}$ and $\delta^{15} \mathrm{~N}$ at Isotrace (Department of Chemistry, University of Otago, New Zealand). Analyses were performed on a Europa Hydra mass spectrometer coupled with a Carlo Erba NA1500 elemental analyser in continuous flow mode (precision: $0.2 \%$ for $\delta^{13} \mathrm{C}$ and $0.3 \%$ for $\left.\delta^{15} \mathrm{~N}\right)$. Analysis was calibrated to international scales using reference materials USGS40 and USGS41.
Quality was monitored using a laboratory standard ethylenediaminetetraacetic acid (EDTA; Elemental Microanalysis). Results are expressed in standard delta notation where, for example, $\delta^{13} \mathrm{C}=\left[R_{\text {sample }}\right]$ $\left.\left.R_{\text {std }}\right)-1\right] \times 1000$ where $R_{\text {sample }}={ }^{13} \mathrm{C}:{ }^{12} \mathrm{C}$ and $R_{\text {std }}=$ ${ }^{13} \mathrm{C}:{ }^{12} \mathrm{C}$ of Vienna Peedee Belemnite limestone. $R_{\text {std }}$ for $\delta^{15} \mathrm{~N}$ was atmospheric nitrogen. Several of the ${ }^{13} \mathrm{C}$-enriched samples had delta values much higher than the highest standards (USGS41 $\delta^{13} \mathrm{C}=+37.63 \%$ ), requiring extrapolation from the calibration. Tests on an enriched sucrose sample known to have $\delta^{13} \mathrm{C}=$ $+400 \%$ showed that the uncertainty was $<2 \%$ at that level.

\section{$\delta^{13} \mathrm{C}$ of individual FAs}

To determine the $\delta^{13} \mathrm{C}$ of individual FAs, samples from Expt 2 were analysed using a Trace GC (Thermo) coupled to a Delta XP IRMS (Finnigan) in the Department of Chemistry, University of Otago. Samples were spiked with an internal standard of nonanoic acid (9:0; Sigma-Aldrich) of known $\delta^{13} \mathrm{C}$. Each sample $(1 \mu \mathrm{l})$ was injected in splitless mode onto a DB225 megabore column (30 m, $0.53 \mathrm{~mm}$ i.d., $1 \mu \mathrm{m}$ film; J \& W Scientific/Agilent). Combustion to $\mathrm{CO}_{2}$ at $940^{\circ} \mathrm{C}$ was assisted by the presence of $\mathrm{CuO}, \mathrm{Pt}$ and $\mathrm{NiO}$ in a micro combustion furnace. Helium was used as the carrier gas and flowed at $4 \mathrm{ml} \mathrm{min}^{-1}$. The initial oven temperature of $125^{\circ} \mathrm{C}$ was ramped to $220^{\circ} \mathrm{C}$ at $2^{\circ} \mathrm{C} \mathrm{min}{ }^{-1}$, then held at this temperature for $11 \mathrm{~min}$. The stability of analysis was monitored with $\mathrm{CO}_{2}$ pulses at the beginning and end of each sample. Isotope ratios were normalized to the international scale using laboratory standard FAMEs of previously determined isotopic composition. The precision of the analysis based on the standard deviation (SD) of repeated analyses of the C9 spike was 0.4 (1 SD, $\mathrm{n}=74)$. FA peaks were identified by retention time matching as described previously. Mass balance equations accounted for methanol added during methylation following the equation: $\delta^{13} \mathrm{C}_{\text {corrected }}=$ $\left(\delta^{13} \mathrm{C}_{\text {output }} \times\left(\mathrm{nC}_{\mathrm{FA}}+1\right)-\delta^{13} \mathrm{C}_{\mathrm{MeOH}}\right) / \mathrm{nC}_{\mathrm{FA}}$ where output refers to the $\delta^{13} \mathrm{C}$ reported by GC-IRMS, $\mathrm{nC}_{\mathrm{FA}}$ is the number of carbons in the FA in question, and $\mathrm{MeOH}$ is the methanol used during derivatisation of the FAME.

\section{Statistical analyses}

To test for differences in the FA composition of seaweeds, a 1-way permutational ANOVA (PERM- 


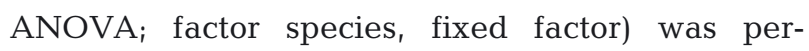
formed on a similarity matrix of Euclidean distances among replicates, using unrestricted permutation of raw data (PERMANOVA; Primer-E). Values of an unidentified $\mathrm{C}_{16}$ PUFA, 18:1 $\omega 7 \mathrm{cis}, 22: 6 \omega 3$ and the unidentified $\mathrm{C}_{22}$ PUFAa were natural log-transformed to improve distribution of residuals. To test for differences in the relative abundance of PUFAs in sandhoppers over time in response to diet, we constructed 1-way PERMANOVAs for Days 1, 4 and 12, with the factor diet (fixed factor), using unrestricted permutation of raw data. Changes in the relative abundance of individual PUFAs over the course of the experiment were then tested using a series of 1-way PERMANOVAs, with the factor diet (fixed factor), using unrestricted permutation of raw data. Note that although the plot (see Fig. 1) uses mean values for each time/diet combination, the PERMANOVA is based on all replicates. One-way PERMANOVAs (factor diet, fixed, unrestricted permutation of raw data) were also used to test for differences in the total concentrations of FAs in sandhoppers fed different diets. All PERMANOVAs outlined above included Monte Carlo tests due to the small number of possible permutations (Anderson et al. 2008). Significant results in the main tests $(\mathrm{p}(\mathrm{MC})<0.05)$ were followed by pairwise PERMANOVAs.

To examine the influence of diet on the metabolic turnover of individual FAs in the sandhoppers, FA turnover was expressed as a proportion of that expected given complete equilibration of $\mathrm{FA} \delta^{13} \mathrm{C}$ to corresponding FA $\delta^{13} \mathrm{C}$ of each diet. These values were then converted into gravimetric amounts of FA turnover, in relation to the concentration of each FA in sandhoppers on Day 17. Values of bulk $\delta^{13} \mathrm{C}$ were then compared to $\delta^{13} \mathrm{C}$ of $\mathrm{FAs}$, where a composite mean value for total FAs was calculated by weighting the $\delta^{13} \mathrm{C}$ of individual FAs to their abundance. For this purpose, values of $\delta^{13} \mathrm{C}$ were available for $\sim 92 \%$ of the total FAs present in sandhoppers. We tested for differences between the $\delta^{13} \mathrm{C}$ of bulk tissues and $\delta^{13} \mathrm{C}$ of FAs using 1-way PERMANOVA (fixed factor), based on Euclidean distance measures using unrestricted permutation of raw data. Monte Carlo tests were included due to the small number of possible permutations.

\section{RESULTS}

\section{FA compositions of seaweeds used in experiments}

The 3 species of seaweed each had distinct FA profiles (Table 1): Durvillaea antarctica was dominated by $18: 1 \omega 9$ (32\% of total FAs) and 16:0 (28\%),

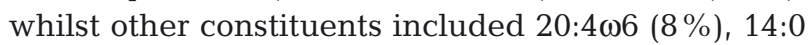
$(7 \%)$ and $20: 5 \omega 3$ (5\%). Ecklonia radiata had a similar FA profile to $D$. antarctica, including high amounts of $18: 1 \omega 9(20 \%)$ and 16:0 (21\%), but also had relatively high amounts of $18: 3 \omega 3(12 \%)$. Other abundant components in E. radiata included 20:4 $\omega 6$ $(11 \%), 20: 5 \omega 3(7 \%)$ and 14:0 (7\%). The most abundant FAs in Ulva sp. included 16:0 (37\%), 18:1 109

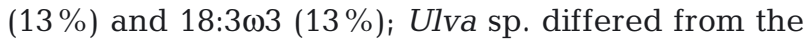
brown seaweeds by the presence of an unidentified

Table 1 . Fatty acid (FA) abundance ( $\%$ total $\mathrm{FA} \pm 1 \mathrm{SE}, \mathrm{n}=3$ replicates) of the 3 seaweed diets (Durvillaea antarctica, Ecklonia radiata and Ulva sp.) and sand hoppers Bellorchestia quoyana at the beginning of Expt 1. PUFA: polyunsaturated FA, c: cis, t: trans, prefix i: iso, prefix a: anteiso. $\mathrm{C}_{20}$ PUFAa and $\mathrm{C}_{20}$ PUFAb are unidentified PUFAs

\begin{tabular}{|lrrrr|}
\hline Fatty acid & D. antarctica & E. radiata & Ulva sp. & B. quoyana \\
\hline $12: 0$ & $0.10 \pm 0.07$ & $0.06 \pm 0.03$ & $0.21 \pm 0.08$ & $2.83 \pm 0.11$ \\
$14: 0$ & $6.67 \pm 0.64$ & $6.62 \pm 0.37$ & $0.85 \pm 0.12$ & $7.59 \pm 0.12$ \\
$i 15: 0$ & $0.88 \pm 0.18$ & $0.40 \pm 0.11$ & $0.08 \pm 0.04$ & $0.28 \pm 0.05$ \\
a15:0 & $0.29 \pm 0.07$ & $0.19 \pm 0.04$ & $0.15 \pm 0.04$ & $0.07 \pm 0.04$ \\
$15: 0$ & $2.73 \pm 0.71$ & $2.84 \pm 0.52$ & $1.89 \pm 0.30$ & $0.05 \pm 0.01$ \\
$\mathrm{C}_{16}$ PUFA & $0.00 \pm 0.00$ & $0.00 \pm 0.00$ & $6.76 \pm 1.53$ & $0.00 \pm 0.00$ \\
$16: 1 \omega 9 \mathrm{C}$ & $2.32 \pm 0.68$ & $1.61 \pm 0.27$ & $1.01 \pm 0.11$ & $0.00 \pm 0.00$ \\
$16: 1 \omega 7 \mathrm{C}$ & $1.46 \pm 0.05$ & $5.25 \pm 0.83$ & $0.61 \pm 0.13$ & $7.37 \pm 0.54$ \\
$16: 1 \omega 5 \mathrm{c}$ & $0.08 \pm 0.01$ & $0.77 \pm 0.07$ & $0.26 \pm 0.11$ & $0.00 \pm 0.00$ \\
$16: 1 \omega 13 \mathrm{t}$ & $0.47 \pm 0.08$ & $0.61 \pm 0.19$ & $1.66 \pm 0.49$ & $0.00 \pm 0.00$ \\
$16: 0$ & $28.00 \pm 1.01$ & $20.92 \pm 0.77$ & $36.93 \pm 2.95$ & $18.24 \pm 0.33$ \\
$18: 4 \omega 3$ & $0.48 \pm 0.17$ & $1.89 \pm 0.43$ & $1.41 \pm 0.42$ & $0.13 \pm 0.01$ \\
$18: 3 \omega 3$ & $3.02 \pm 0.71$ & $12.30 \pm 1.95$ & $13.40 \pm 0.96$ & $0.73 \pm 0.02$ \\
$18: 2 \omega 6$ & $2.87 \pm 0.26$ & $2.23 \pm 0.15$ & $2.83 \pm 0.86$ & $2.68 \pm 0.13$ \\
$18: 1 \omega 9 \mathrm{C}$ & $32.05 \pm 0.95$ & $20.47 \pm 0.49$ & $12.79 \pm 2.05$ & $41.43 \pm 0.67$ \\
$18: 1 \omega 7 \mathrm{C}$ & $0.14 \pm 0.05$ & $0.13 \pm 0.04$ & $11.81 \pm 1.10$ & $2.58 \pm 0.12$ \\
$18: 1 \omega 7 \mathrm{t}$ & $0.12 \pm 0.03$ & $0.16 \pm 0.07$ & $0.32 \pm 0.15$ & $0.06 \pm 0.05$ \\
$18: 1 \omega 5 \mathrm{c}$ & $0.02 \pm 0.01$ & $0.07 \pm 0.02$ & $0.00 \pm 0.00$ & $0.07 \pm 0.00$ \\
$18: 0$ & $2.58 \pm 0.34$ & $1.28 \pm 0.07$ & $0.99 \pm 0.09$ & $2.12 \pm 0.16$ \\
$20: 4 \omega 6$ & $8.12 \pm 1.10$ & $11.24 \pm 0.39$ & $0.13 \pm 0.02$ & $5.43 \pm 0.28$ \\
$20: 5 \omega 3$ & $4.70 \pm 1.01$ & $6.87 \pm 0.55$ & $0.50 \pm 0.13$ & $1.76 \pm 0.10$ \\
$\mathrm{C}_{20}$ PUFAa & $0.58 \pm 0.14$ & $0.50 \pm 0.06$ & $0.08 \pm 0.02$ & $0.46 \pm 0.01$ \\
$\mathrm{C}_{20}$ PUFAb & $0.61 \pm 0.20$ & $0.73 \pm 0.06$ & $0.81 \pm 0.18$ & $0.50 \pm 0.05$ \\
$20: 1 \omega 11 \mathrm{c}$ & $0.18 \pm 0.04$ & $0.20 \pm 0.05$ & $0.17 \pm 0.08$ & $0.39 \pm 0.06$ \\
$20: 1 \omega 9 \mathrm{C}$ & $0.10 \pm 0.04$ & $0.26 \pm 0.07$ & $0.14 \pm 0.03$ & $3.15 \pm 0.10$ \\
$20: 1 \omega 7 \mathrm{C}$ & $0.07 \pm 0.02$ & $0.12 \pm 0.05$ & $0.24 \pm 0.06$ & $0.70 \pm 0.04$ \\
$20: 0$ & $0.78 \pm 0.06$ & $1.09 \pm 0.06$ & $0.22 \pm 0.02$ & $0.60 \pm 0.23$ \\
$22: 6 \omega 3$ & $0.00 \pm 0.00$ & $0.05 \pm 0.03$ & $0.01 \pm 0.00$ & $0.03 \pm 0.01$ \\
$\mathrm{C}_{22} \mathrm{PUFAa}$ & $0.00 \pm 0.00$ & $0.34 \pm 0.07$ & $0.02 \pm 0.00$ & $0.18 \pm 0.02$ \\
$\mathrm{C}_{22} \mathrm{PUFAb}$ & $0.00 \pm 0.00$ & $0.53 \pm 0.09$ & $1.60 \pm 0.07$ & $0.06 \pm 0.01$ \\
$22: 0$ & $0.60 \pm 0.04$ & $0.27 \pm 0.13$ & $2.09 \pm 0.23$ & $0.60 \pm 0.23$ \\
& & & & \\
\hline
\end{tabular}




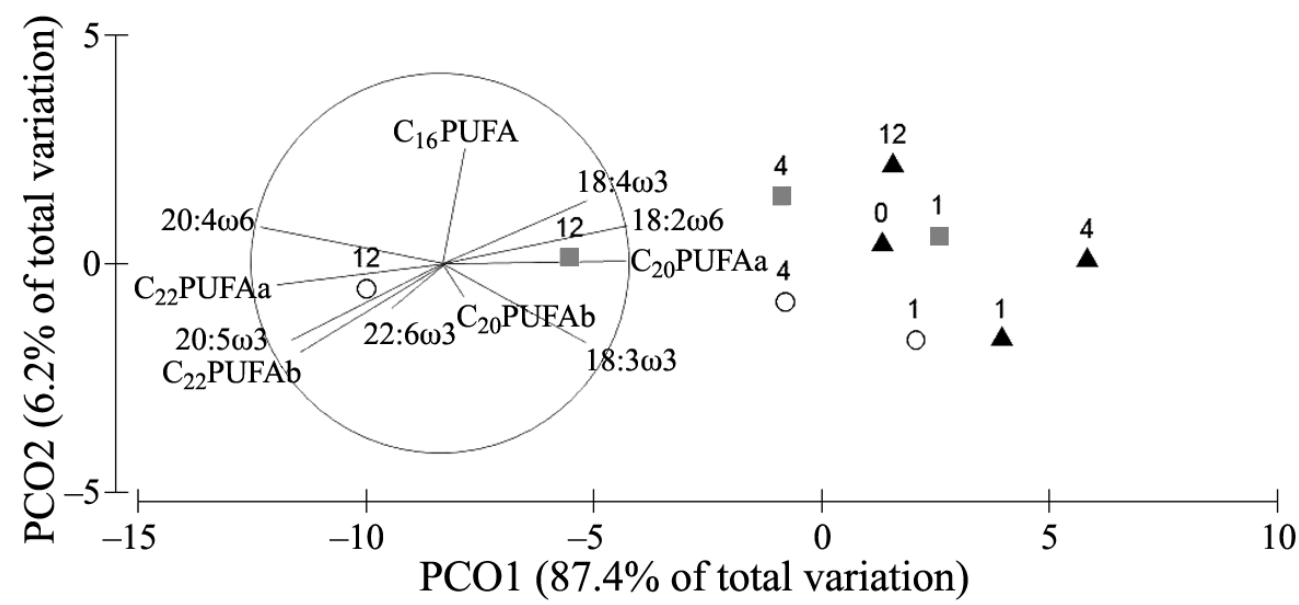

Fig. 1. Bellorchestia quoyana. Principal Coordinates Analysis (PCO) plot of compositions of polyunsaturated fatty acids (\% total PUFAs) in sandhoppers on Days 0, 1, 4 and 12, fed either Durvillaea antarctica ( $\mathbf{(})$, Ecklonia radiata ( $\square)$ or Ulva sp. (o). Points represent average values for replicates $(n=3)$ of each day and diet. Vectors indicate the general direction of increase for quantities of individual FAs, and the proximity to the edge of the vector circle indicates the strength of such correlations (Note: these relationships may not be linear so are to be used only as an indication). a and b denote PUFA compounds for which the placement of double bonds was not determined

$\mathrm{C}_{16}$ PUFA (7\%), moderate amounts of $18: 1 \omega 7(12 \%)$

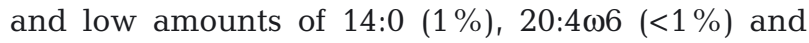
$20: 5 \omega 3(<1 \%)$. The FA profiles of each species were significantly different from each other (PERMANOVA MS: $1846, F=29.45, \mathrm{p}($ perm $)=0.0001$; pairwise $\mathrm{p}($ perm $)<0.005$; Ulva $\mathrm{sp} . \neq E$. radiata $\neq D$. antarctica).

Table 2. Bellorchestia quoyana. Results of 1-way PERMANOVA for each time over the course of $12 \mathrm{~d}$, based on comparisons of relative amounts of polyunsaturated fatty acids (PUFAs) in sandhoppers fed either Durvillaea antarctica (D), Ecklonia radiata (E) or Ulva sp. (U). Significant results in main tests were followed by pairwise tests. Significant results based on Monte Carlo $(\mathrm{MC})(\mathrm{p}<0.05)$ are indicated in bold

\begin{tabular}{|lcccc|}
\hline Day & df & $F$ & $p$ & $p(M C)$ \\
\hline 1 & 8 & 0.7965 & 0.6379 & 0.585 \\
4 & 8 & 5.4907 & 0.0258 & $\mathbf{0 . 0 1 3 1}$ \\
12 & 8 & 7.3488 & 0.0044 & $\mathbf{0 . 0 0 3 9}$ \\
Day 4 pairwise & $t$ & $p$ & Unique perms & $\mathrm{p}(\mathrm{MC})$ \\
\hline U,E & 0.95394 & 0.6935 & 10 & 0.4494 \\
U,D & 2.5894 & 0.1025 & 10 & $\mathbf{0 . 0 3 4 9}$ \\
D,E & 3.0793 & 0.0982 & 10 & $\mathbf{0 . 0 1 3 5}$ \\
Day 12 pairwise & $t$ & $\mathrm{p}$ & Unique perms & $\mathrm{p}(\mathrm{MC})$ \\
\hline U,E & 1.7209 & 0.0997 & 10 & 0.0907 \\
U,D & 3.6188 & 0.1031 & 10 & $\mathbf{0 . 0 0 7 9}$ \\
D,E & 2.4165 & 0.1006 & 10 & $\mathbf{0 . 0 2 8 2}$ \\
\hline
\end{tabular}

\section{Expt 1: Does diet change the composition of FAs and $\delta^{15} \mathrm{~N}$ and $\delta^{13} \mathrm{C}$ in sandhoppers?}

Consumption rates were comparable across the 3 diets, with mean consumption of macroalgal diets after $17 \mathrm{~d}$ (corrected for autogenic changes in seaweed deduced from the controls) of $18.4 \pm 1.7 \mathrm{SD} \%$ (blotted wet weight) for Ulva sp., $17.7 \pm 11.3 \%$ for Ecklonia radiata, and $20.8 \pm 7.0 \%$ for Durvillaea antarctica. This equated to consumption per sandhopper of $0.16 \pm 0.01 \mathrm{~g}$ for Ulva sp., $0.38 \pm 0.07 \mathrm{~g}$ for $E$. radiata and $0.40 \pm 0.05 \mathrm{~g}$ for $D$. antarctica. The FA composition changed the most over time in sandhoppers fed Ulva sp. and E. radiata (Fig. 1). By Day 4, the PUFA compositions of sandhoppers fed Ulva sp. and E. radiata were significantly different from those fed $D$. antarctica, and this pattern held until Day 12 (Table 2). Over time, sandhoppers fed E. radiata and Ulva sp. exhibited a significant decrease in the rela-

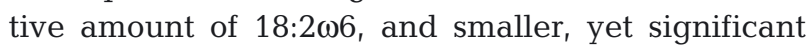

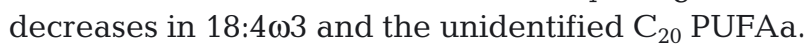
Significant increases were measured in the relative

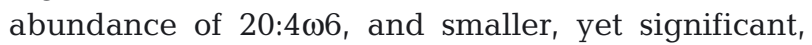
increases in the unidentified $\mathrm{C}_{22}$ PUFAa and $\mathrm{C}_{22}$ PUFAb (Fig. 2). Sandhoppers fed Ulva sp. had a significant increase in the relative amount of 20:5 03 after $12 \mathrm{~d}$ (Fig. 2). There were no significant changes to PUFA abundance in sandhoppers fed $D$. antarctica. By Day 12 of the experiment, sandhoppers fed Ulva sp. and E. radiata lost condition compared to those fed $D$. antarctica, as indicated by the reduced total FA concentrations of those sandhoppers (Fig. 3). 


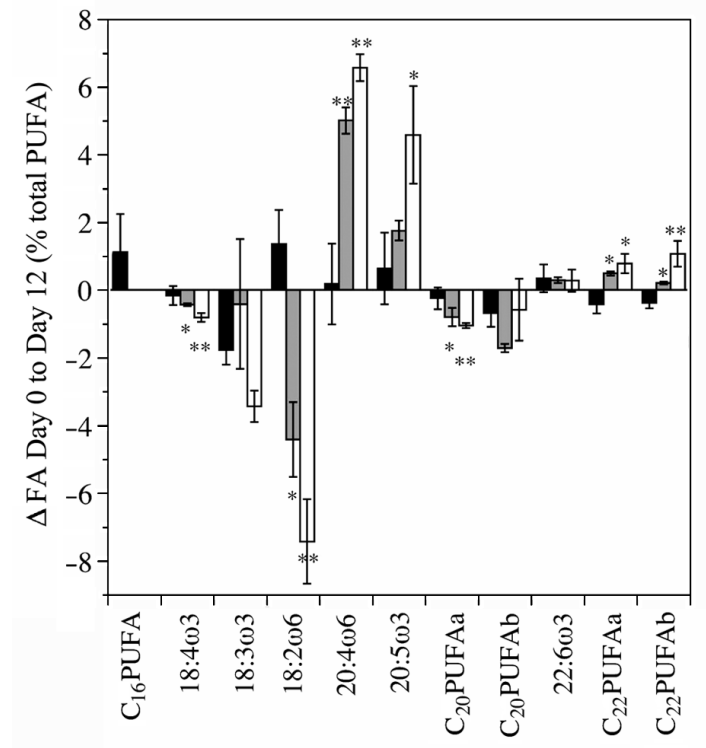

Fig. 2. Bellorchestia quoyana. Change in relative abundance of polyunsaturated fatty acids (PUFAs) in sandhoppers (mean $\pm 1 \mathrm{SE}, \mathrm{n}=3$ replicates) after $12 \mathrm{~d}$ fed either Durvillaea antarctica (black), Ecklonia radiata (grey) or Ulva sp. (white). Significant differences among treatments are indicated by * where Monte-Carlo $\mathrm{p}<0.05$, and ${ }^{* *}$ where Monte-Carlo $\mathrm{p}<0.005$

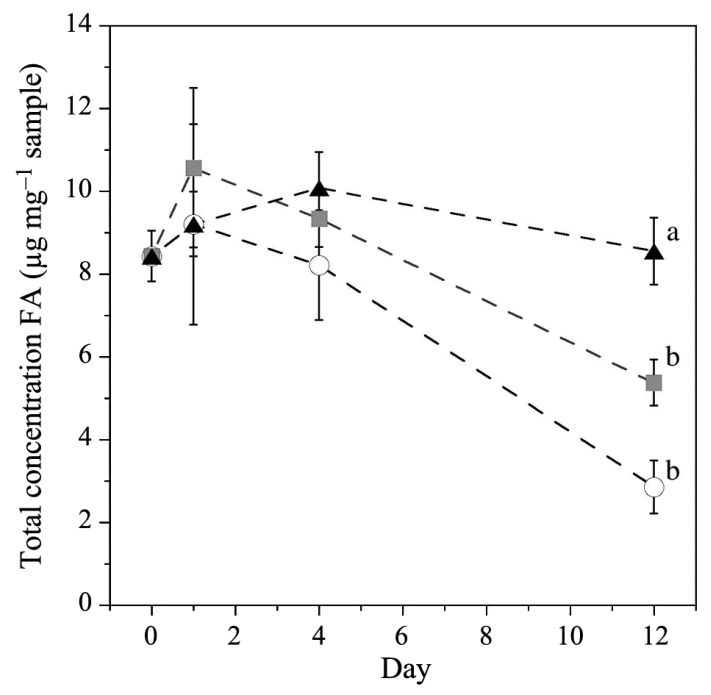

Fig. 3. Bellorchestia quoyana. Total fatty acid (FA) concentration of sandhoppers on Days 0, 1, 4 and 12 (mean $\pm 1 \mathrm{SE}$, $\mathrm{n}=3$ replicates) fed either Durvillaea antarctica (4), Ecklonia radiata ( $\square$ ) or Ulva sp. (०). Results of pairwise PERMANOVA tests indicate significant differences among treatments not connected by the same letters (Monte-Carlo $\mathrm{p}<0.05$ )

Values of $\delta^{15} \mathrm{~N}$ and $\delta^{13} \mathrm{C}$ of 'bulk' sandhoppers did not change significantly in response to diet over the $12 \mathrm{~d}$ of the experiment (Fig. 4). Values of $\delta^{15} \mathrm{~N}$ remained at $\sim 10 \%$, being $\sim 3 \%$ higher than the Durvillaea antarctica wrack from which they were originally sourced. Values of $\delta^{13} \mathrm{C}$ were similarly static at ca. $-14 \%$, which was comparable to the source D. antarctica (see Fig. 4).

\section{Expt 2: Does diet influence the turnover and biosynthesis of FAs in sandhoppers?}

Values of $\delta^{13} \mathrm{C}$ of Ulva sp. and Ecklonia radiata grown in ${ }^{13} \mathrm{C}$-elevated media were both raised to $\sim 1300 \%$. Sandhoppers fed these ${ }^{13} \mathrm{C}$-enriched seaweeds showed consistent increases in $\delta^{13} \mathrm{C}$ of bulk tissues, with Day 17 values of $172 \pm 28 \%$ for those fed ${ }^{13} \mathrm{C}$-enriched $E$. radiata, and $86 \pm 21 \%$ for those fed ${ }^{13} \mathrm{C}$-enriched Ulva
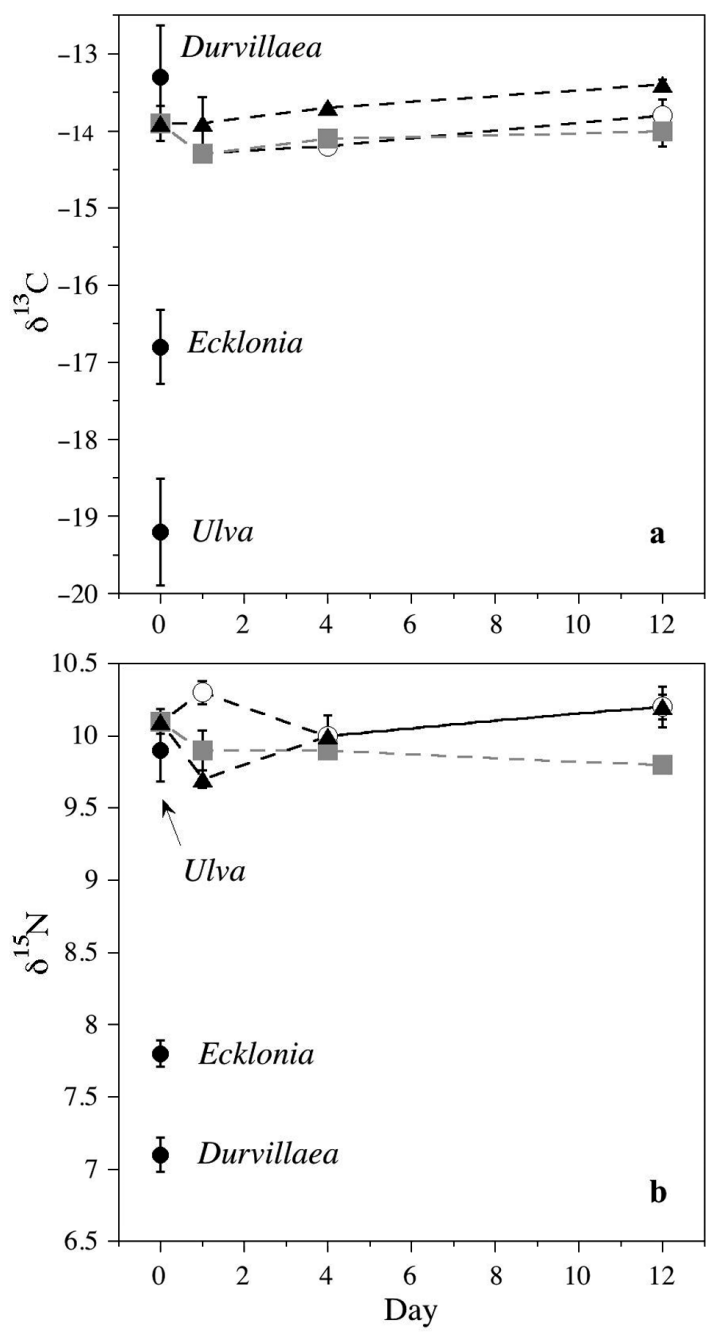

Fig. 4. Bellorchestia quoyana. (a) $\delta^{13} \mathrm{C}$ and (b) $\delta^{15} \mathrm{~N}$ values of sandhoppers (\%, mean $\pm 1 \mathrm{SE}, \mathrm{n}=3$ or 4 replicates) fed either Durvillaea antarctica (ム), Ecklonia radiata ( $\square$ ) or Ulva sp. (०) for $12 \mathrm{~d}$. Note that sandhoppers were collected $2 \mathrm{~d}$ prior to the experiment commencing from a natural setting underneath $D$. antarctica wrack. Isotopic ratios of each food source ( $\mathrm{n}=4$ replicates) are provided $(\bullet)$ 
sp. (Fig. 5). These values equate to a $31 \%$ turnover of carbon in E. radiata-fed sandhoppers over $17 \mathrm{~d}$, and an $8 \%$ carbon turnover in those fed Ulva sp. Although the experiment was terminated at this point, there was no sign of $\delta^{13} \mathrm{C}$ values of sandhoppers reaching equilibrium with their diets. $\delta^{13} \mathrm{C}$ of sandhoppers fed natural, unlabelled E. radiata and Ulva sp. remained constant and unchanged throughout the course of the experiment (Fig. 5).

Due to the low number of FAs that were common for both Ulva sp. and sandhoppers, calculations of FA turnover for sandhoppers in this treatment was

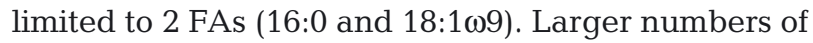
common FAs between sandhoppers and Ecklonia radiata provided an opportunity for a more thorough assessment of FA turnover with respect to this diet. There were substantial differences in the amount of turnover of individual FAs under the different diet treatments (Fig. 6), with sandhoppers fed E. radiata (Fig. 6a) exhibiting a far greater turnover of individual FAs than those fed Ulva sp. (Fig. 6b). For example, on Day 17, sandhoppers fed Ulva sp. had turned over $51.9 \pm 16.6 \mathrm{ng} \mathrm{mg}^{-1}$ of 16:0, compared to $306.8 \pm$ $83.8 \mathrm{ng} \mathrm{mg}^{-1}$ for sandhoppers fed E. radiata. For the $E$. radiata treatment, the largest amounts of turnover occurred in 18:1 $\omega 9$ and 16:0. The FA 20:5 $\omega 3$ had a relatively delayed turnover, with the majority occurring between Days 12 and 17. For sandhoppers in the Ulva sp. treatment, turnover was similar for 16:0 and 18:1 $\omega 9$. This analysis of FA turnover in units of concentration does not take into account the quantity of each FA in the sandhoppers, so values were translated

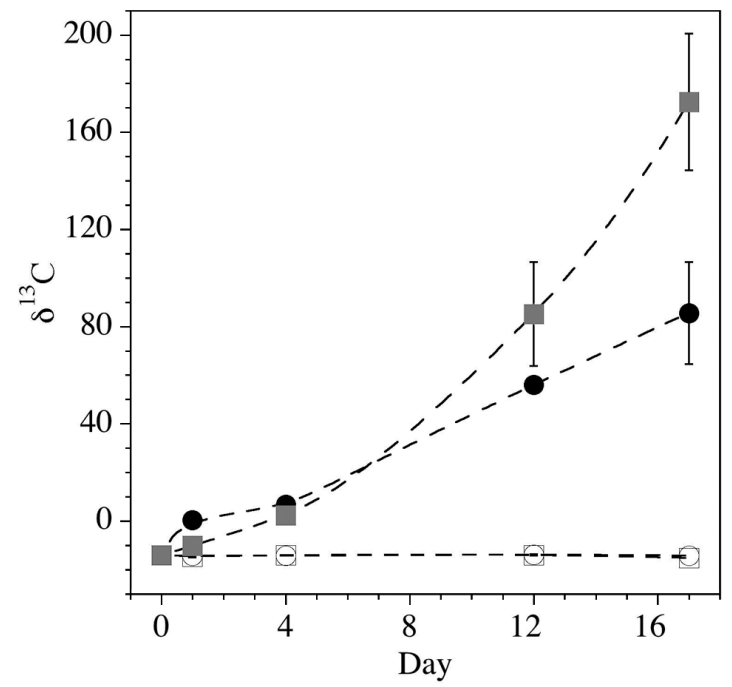

Fig. 5. Bellorchestia quoyana. Values of sandhopper bulk $\delta^{13} \mathrm{C}(\%$, mean $\pm 1 \mathrm{SE}, \mathrm{n}=3$ replicates) fed either ${ }^{13} \mathrm{C}$-enhanced Ecklonia radiata $(\square)$, natural E. radiata (口), ${ }^{13} \mathrm{C}$-enhanced Ulva sp. (•), or natural Ulva sp. (O) for $17 \mathrm{~d}$ into proportions of the quantity of each FA (Fig. 6c,d). The highest proportional turnover in the E. radiata

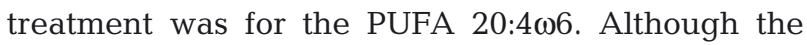
quantity (concentration) of 18:1 19 turned over was high, this was the dominant FA in sandhoppers, and thus the proportional turnover of this FA was low. Proportional FA turnover in sandhoppers fed Ulva sp.

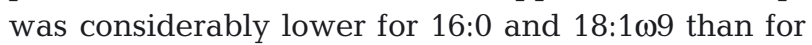
any of the measured FAs in the E. radiata treatment.

Changes to $\delta^{13} \mathrm{C}$ over time for bulk values and for the FA fraction under the 2 diet treatments are compared in Fig. 7. For the Ecklonia radiata treatment, bulk and FA $\delta^{13} \mathrm{C}$ varied similarly throughout the $17 \mathrm{~d}$ of the experiment. In contrast, sandhoppers fed Ulva sp. had significantly lower values of $\delta^{13} \mathrm{C}$ for the FAs than the bulk $\delta^{13} \mathrm{C}$ on Days 1 and 12 (Fig. 7b), and at the termination of the trial, these values appeared to be diverging.

\section{DISCUSSION}

As the use of FA biomarkers becomes popular in coastal food web studies, it is increasingly important to improve the understanding of transformations that may occur during the assimilation of FAs by consumers. It is likely that the trophic transfer of FAs from source to consumer varies among consumer taxa, making taxon-specific feeding studies essential to support the application of FAs as dietary biomarkers at the community level. To the best of our knowledge, this is the first study examining potential FA biomarkers for diet in talitrid amphipods. These amphipods are among the dominant consumers in shoreline habitats and contribute as food to higher trophic levels (Dugan et al. 2003, Hubbard \& Dugan 2003).

Despite $\delta^{13} \mathrm{C}$ and $\delta^{15} \mathrm{~N}$ of bulk tissues of the 3 seaweed diets differing substantially, no change was observed in $\delta^{13} \mathrm{C}$ and $\delta^{15} \mathrm{~N}$ of sandhoppers in response to diet at the end of the $12 \mathrm{~d}$ experiment. There were signs of consumption for all 3 diets, including considerably higher loss of algae in treatments relative to autogenic controls and the presence of grazing marks. The algal diets were consumed in similar amounts, ranging from 0.16 to $0.40 \mathrm{~g}$ per sandhopper over the experimental period. The lack of change in these isotope ratios therefore indicates that the turnover of carbon and nitrogen in sandhoppers under these conditions occurs at a rate significantly slower than was detectable within $12 \mathrm{~d}$, and therefore, natural abundance bulk isotopes do not provide an appropriate measure of short-term dietary shifts for this species under these experimental conditions. We are unaware 

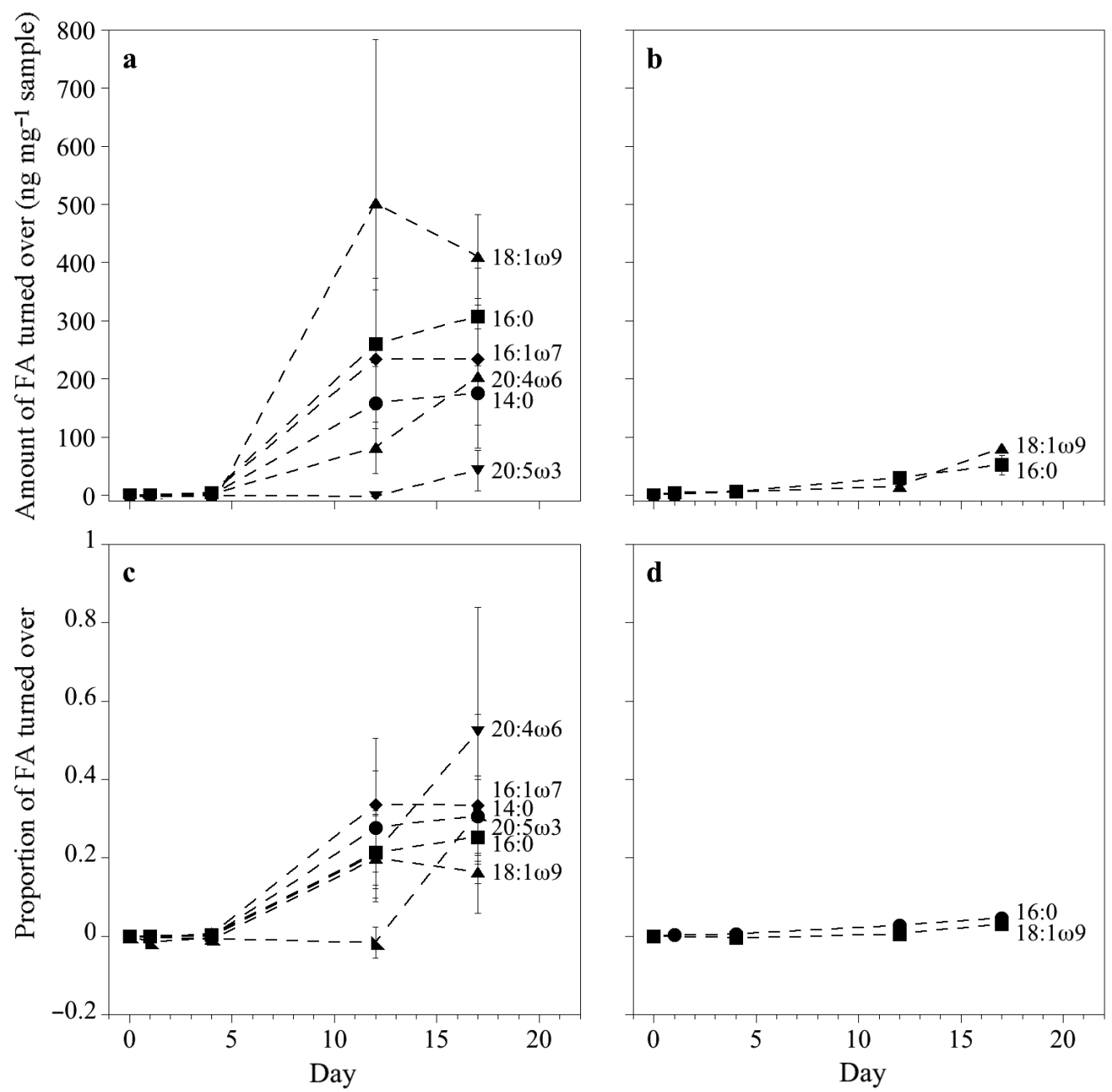

Fig. 6. Bellorchestia quoyana. Quantity of turnover of individual fatty acids (FAs) for sandhoppers fed (a) Ecklonia radiata or (b) Ulva sp., and turnover of individual FAs as a proportion of the $\delta^{13} \mathrm{C}$ of their diets of (c) E. radiata or (d) Ulva sp. during the course of the $17 \mathrm{~d}$ experiment. Mean values of 3 replicates are provided $( \pm 1 \mathrm{SE})$
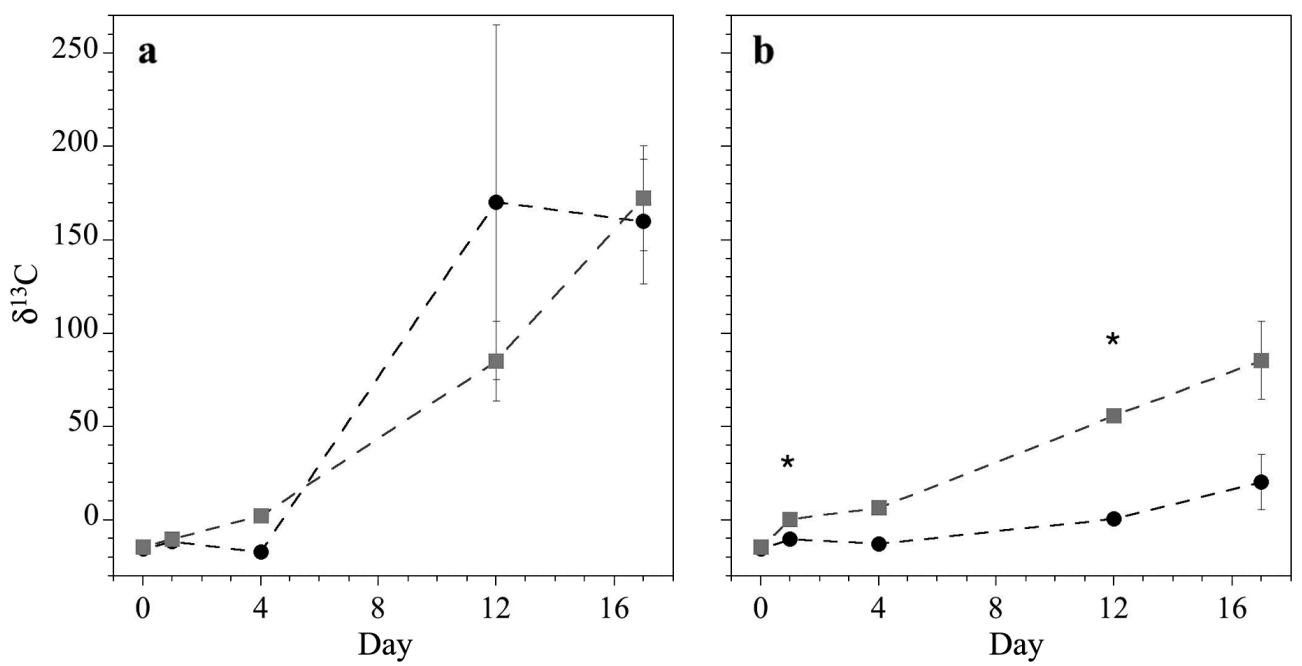

Fig. 7. Bellorchestia quoyana. Bulk $\delta^{13} \mathrm{C}\left(\%,{ }^{-}\right)$and $\delta^{13} \mathrm{C}$ of total fatty acids (FAs; weighted mean, $\bullet$ ) of sandhoppers fed (a) Ecklonia radiata or (b) Ulva sp., during the course of the $17 \mathrm{~d}$ experiment. Mean values of 3 replicates are shown ( $\pm 1 \mathrm{SE}$ ), with the exception of the Ulva sp. treatment on Day $4(\mathrm{n}=2)$. ${ }^{*}$ Significant differences (Monte-Carlo $\left.\mathrm{p} \leq 0.05\right)$ between $\delta^{13} \mathrm{C}$ values of bulk and FA sandhoppers 
of any measurements of tissue turnover rates for this species; however, small crustaceans such as shrimp have been reported to have muscle tissue half lives on the scale of weeks (Fry et al. 2003), and larger, slowgrowing crustaceans such as rock lobster on the scale of months (Suring \& Wing 2009). The implications of such time scales gives merit to the search for dietary biomarkers (other than stable isotopes of bulk tissues) that respond over shorter time periods, and also for using artificially enhanced ${ }^{13} \mathrm{C}$ in seaweeds as a tool for tracing diet.

We found the FA composition and turnover of individual FAs of the amphipod Bellorchestia quoyana to be influenced by the FA composition of select seaweed diets, but not in the manner that we expected. We hypothesized that a PUFA-deficient diet would result in decreased PUFA concentration in sandhoppers and vice versa. Ulva sp. are deficient in longchain PUFAs, which are required by many invertebrate and fish species to maintain optimum health (Parrish 2009). Ecklonia radiata has a similar FA composition to Durvillaea antarctica in this respect, being rich in long-chain PUFAs. However, sandhoppers fed Ulva sp. had significantly greater relative abun-

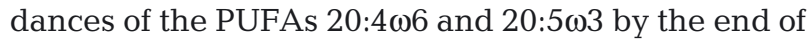
the experiment (Day 12). For the sandhoppers fed $E$.

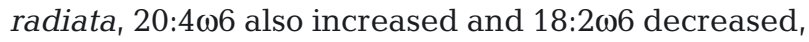
whilst the $D$. antarctica treatment did not cause a significant change in the FA composition of sandhoppers, which was expected given that the sandhoppers were sourced from beach-cast D. antarctica.

A decline of total FA concentration over time in sandhoppers fed Ulva sp. and Ecklonia radiata provides an indication that the overall condition of consumers under these treatments deteriorated between Days 4 and 12. It could be argued that the changes in the FA compositions of sandhoppers under these treatments were due to starvation. However, as discussed previously, positive signs of consumption of all diets were observed and measured, suggesting that despite being palatable, these diets were in some way not nutritionally adequate to maintain sandhopper condition. The Ulva sp. and the E. radiata diets resulted in the greatest differences in sandhopper FA composition and total FA concentration. The inconsistent relationship between sandhopper and dietary PUFAs was likely due to differences in the proportional metabolism of polar and neutral FA fractions. Neutral lipids are abundant storage products and are catabolized to provide energy (Dalsgaard et al. 2003). The neutral lipid fraction is believed to be the most responsive to changes in dietary FAs (Bourdier \& Amblard 1989, Dalsgaard et al. 2003, Caramujo et al.
2008, Brett et al. 2009). It is possible that, under conditions of diet deficiency or starvation, the proportional amount of neutral FAs would therefore decrease (e.g. Caramujo et al. 2008). Were the majority of PUFAs to be present in the polar fraction, as has been observed for brine shrimp (Jezyk \& Penicnak 1966) and some marine amphipods (Graeve et al. 2001), this decrease in neutral FAs would result in an apparent increase in PUFAs in the total FAs. However, in a study of the FA composition of a diverse range of Antarctic benthic amphipods, Graeve et al. (2001) found only small differences in the FA compositions of these 2 fractions, which indicated that the amphipods had high plasticity in both their storage and membrane lipids in response to diet. An alternative explanation for our findings could be incorporation of bacterially produced PUFAs, associated with Ulva sp. or gut flora of the sandhoppers (Jøstensen \& Landfald 1997, Nichols 2003, Bell et al. 2007). We were unable to discriminate or define such interactions in the current study.

In Expt 2, uptake of ${ }^{13} \mathrm{C}$ from artificially labelled Ulva sp. and Ecklonia radiata was evident in bulk tissue isotope measurements and in individual FAs, allowing for estimations of carbon turnover. It was apparent that whilst both Ulva $\mathrm{sp}$. and E. radiata were assimilated by sandhoppers, assimilation of $E$. radiata occurred at a significantly higher rate than Ulva sp. Uptake of ${ }^{13} \mathrm{C}$ into individual FAs was higher for the E. radiata diet, indicating that FA metabolism in sandhoppers can be regulated according to diet. Of particular interest was the relative amount of ${ }^{13} \mathrm{C}$ assimilated by bulk tissues compared to individual FAs under both dietary treatments. Whilst $\delta^{13} \mathrm{C}$ in bulk tissues was comparable among the 2 treatments until Day 12, the turnover rates of 16:0 and 18:1 19 were significantly higher in the E. radiata treatment. This finding suggests that carbon turnover and metabolism of sandhoppers in the Ulva sp. treatment was occurring in fractions other than FAs. Although we were not able to include Durvillaea antarctica in this experiment, it is likely that the carbon turnover of FAs and bulk tissues of sandhoppers fed D. antarctica would be similar or greater than that measured for E. radiata. This hypothesis is based on the indications in the first experiment that sandhoppers maintained optimum condition when fed $D$. antarctica.

We did not find a consistent relationship between the FA composition of different seaweed species and the littoral sandhoppers. Despite providing diets that differed markedly in the quantity of long-chain PUFAs, the PUFA composition of sandhoppers did not change in a manner that was consistent with the abundances of PUFAs in the diet. Similar incon- 
sistencies in the relationship between dietary and assimilated FAs have been reported for other crustaceans. Daphnia pulex was found to accumulate 20:5 $\omega 3$ when fed a green algae diet lacking in this

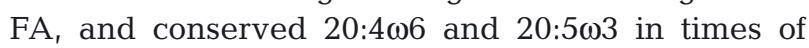
starvation (Schlechtriem et al. 2006). The authors of that study postulated that this finding was due to conversion of $\mathrm{C}_{18}$ PUFAs to these $\mathrm{C}_{20}$ PUFAs. Similarly, the freshwater copepod Eucydops serrulatus accumulated 22:6 $\omega 3$ when fed green algae lacking in this FA, which was attributed to biosynthesis from 18:303 (Desvilettes et al. 1997). Evidence to date suggests that many herbivorous crustaceans have the ability to convert $18: 3 \omega 3$ to $20: 5 \omega 3$ and $22: 6 \omega 3$, but with varying degrees of efficiency (Caramujo et al. 2008). Due to variability in the total FA concentration among diet treatments in the current study, it was not possible to make meaningful comparisons regarding changes in the absolute concentration of specific FAs in sandhoppers. Questions regarding potential biosynthesis of long-chain PUFAs in relation to diet could therefore not be addressed.

Whilst the trophic transfer of FAs from diet to consumer has been shown in some cases to provide dietary markers (e.g. Dalsgaard et al. 2003, Graeve et al. 2005, Kelly et al. 2009), such transfer is not necessarily straightforward, in that the FA composition of consumers is likely also influenced by factors including diet quality, physiological status of the consumer and variability in metabolism and turnover of FAs in response to these factors. Differences in growth rates, gut flora and the degree of dietary specialization could also influence the assimilation and transformation of diet-sourced FAs, and thus the appropriateness of FAs as dietary biomarkers may differ among taxa. We caution against the use of a broadbrush approach to FAs as biomarkers in communitylevel studies, as different groups and classes of benthic fauna are likely to metabolize FAs in different manners, and thus the transfer of FAs from source to consumer is unlikely to be consistent or predictable among taxa. Studies using FAs as dietary indicators in the natural environment must therefore be supported by carefully designed feeding studies.

Acknowledgements. We thank S. Bell, C. Cornwall, D. Pritchard, D. Richards, C. Hepburn and R. Win for assistance with the laboratory experiments and collection of seaweeds, and R. Suarez Jimenez for providing valuable insights. Logistic and practical support was provided by the Departments of Chemistry and Botany at the University of Otago. The comments of 4 anonymous reviewers were gratefully received. This work was funded by a Foundation for Research, Science and Technology (FRST) Science and
Technology Postdoctoral Fellowship to R.J.M (UOOX0814), and a FRST subcontract to C.L.H. from the National Institute of Water and Atmospheric Research Ltd., Biodiversity and Biosecurity OBI (C01X0502).

\section{LITERATURE CITED}

Alfaro AC, Thomas F, Sergent L, Duxbury M (2006) Identification of trophic interactions within an estuarine food web (northern New Zealand) using fatty acid biomarkers and stable isotopes. Estuar Coast Shelf Sci 70:271-286

Anderson MJ, Gorley RN, Clarke KR (2008) PERMANOVA+ for PRIMER: guide to software and statistical methods. PRIMER-E, Plymouth

Auel H, Harjes M, da Rocha R, Stübing D, Hagen W (2002) Lipid biomarkers indicate different ecological niches and trophic relationships of the Arctic hyperiid amphipods Themisto abyssorum and T. libellula. Polar Biol 25:374-383

Bachok Z, Mfilinge PL, Tsuchiya M (2003) The diet of the mud clam Geloina coaxans (Mollusca, Bivalvia) as indicated by fatty acid markers in a subtropical mangrove forest of Okinawa, Japan. J Exp Mar Biol Ecol 292: 187-197

Bell MV, Tocher DR (2009) Biosynthesis of polyunsaturated fatty acids in aquatic ecosystems: general pathways and new directions. In: Arts MT, Brett MT, Kainz M (eds) Lipids in aquatic ecosystems. Springer-Verlag, New York, NY, p 211-236

Bell MV, Dick JR, Anderson TR, Pond DW (2007) Application of liposome and stable isotope tracer techniques to study polyunsaturated fatty acid biosynthesis in marine zooplankton. J Plankton Res 29:417-422

Bligh EG, Dyer WJ (1959) A rapid method of total lipid extraction and purification. Can J Biochem Physiol 37: 911-917

Boschker HTS, Middelburg JJ (2002) Stable isotopes and biomarkers in microbial ecology. FEMS Microbiol Ecol 40:85-95

Bourdier GG, Amblard CA (1989) Lipids in Acanthodiaptomus denticornis during starvation and fed on three different algae. J Plankton Res 11:1201-1212

Brett MT, Müller-Navarra DC, Persson J (2009) Crustacean zooplankton fatty acid composition. In: Arts MT, Brett MT, Kainz M (eds) Lipids in aquatic ecosystems. Springer-Verlag, New York, NY, p 115-146

> Budge SM, Wooller MJ, Springer AM, Iverson SJ, McRoy CP, Divoky GJ (2008) Tracing carbon flow in an arctic marine food web using fatty acid-stable isotope analysis. Oecologia 157:117-129

Caramujo MJ, Boschker HTS, Admiraal W (2008) Fatty acid profiles of algae mark the development and composition of harpacticoid copepods. Freshw Biol 53:77-90

> Caut S, Angulo E, Courchamp F (2009) Variation in discrimination factors $\left(\delta^{15} \mathrm{~N}\right.$ and $\left.\delta^{13} \mathrm{C}\right)$ : the effect of diet isotopic values and applications for diet reconstruction. J Appl Ecol 46:443-453

> Connolly RM, Hindell JS, Gorman D (2005) Seagrass and epiphytic algae support nutrition of a fisheries species, Sillago schomburgkii, in adjacent intertidal habitats. Mar Ecol Prog Ser 286:69-79

Crawley KR, Hyndes GA, Vanderklift MA (2007) Variation among diets in discrimination of $\delta^{13} \mathrm{C}$ and $\delta^{15} \mathrm{~N}$ in the amphipod Allorchestes compressa. J Exp Mar Biol Ecol 349:370-377

Crawley KR, Hyndes GA, Vanderklift MA, Revill AT, Nichols PD (2009) Allochthonous brown algae are the primary 
food source for consumers in a temperate, coastal environment. Mar Ecol Prog Ser 376:33-44

- Dalsgaard J, St. John M, Kattner G, Müller-Navarra D, Hagen W (2003) Fatty acid trophic markers in the pelagic marine environment. Adv Mar Biol 46:225-340

> Desvilettes C, Bourdier G, Breton JC (1997) On the occurrence of a possible bioconversion of linolenic acid into docosahexaenoic acid by the copepod Eucyclops serrulatus fed on microalgae. J Plankton Res 19:273-278

Dugan JE, Hubbard DM, McCrary MD, Pierson MO (2003) The response of macrofauna communities and shorebirds to macrophyte wrack subsidies on exposed sandy beaches of southern California. Estuar Coast Shelf Sci 58(Suppl):25-40

Fry B (2006) Stable isotope ecology. Springer, New York, NY

$>$ Fry B, Baltz DM, Benfield MC, Fleeger JW, Gace A, Haas HL, Quiñones-Rivera ZJ (2003) Stable isotope indicators of movement and residency for brown shrimp (Farfantepenaeus aztecus) in coastal Louisiana marshscapes. Estuaries 26:82-97

> Graeve M, Kattner G, Hagen W (1994) Diet-induced changes in the fatty acid composition of Arctic herbivorous copepods: experimental evidence of trophic markers. J Exp Mar Biol Ecol 182:97-110

> Graeve M, Dauby P, Scailteur Y (2001) Combined lipid, fatty acid and digestive tract content analyses: a penetrating approach to estimate feeding modes of Antarctic amphipods. Polar Biol 24:853-862

Graeve M, Albers C, Kattner G (2005) Assimilation and biosynthesis of lipids in Arctic Calanus species based on feeding experiments with a ${ }^{13} \mathrm{C}$ labelled diatom. J Exp Mar Biol Ecol 317:109-125

> Guest MA, Nichols PD, Frusher SD, Hirst AJ (2008) Evidence of abalone (Haliotis rubra) diet from combined fatty acid and stable isotope analyses. Mar Biol 153: 579-588

Hanson CE, Hyndes GA, Wang SF (2010) Differentiation of benthic marine primary producers using stable isotopes and fatty acids: implications to food web studies. Aquat Bot 93:114-122

> Hubbard DM, Dugan JE (2003) Shorebird use of an exposed sandy beach in southern California. Estuar Coast Shelf Sci 58(Suppl):41-54

Hyndes GA, Lavery PS (2005) Does transported seagrass provide an important trophic link in unvegetated, nearshore areas? Estuar Coast Shelf Sci 63:633-643

> Ince R, Hyndes GA, Lavery PS, Vanderklift MA (2007) Marine macrophytes directly enhance abundances of sandy beach fauna through provision of food and habitat. Estuar Coast Shelf Sci 74:77-86

- Jezyk PF, Penicnak AJ (1966) Fatty acid relationships in an aquatic food chain. Lipids 1:427-429

Jøstensen JP, Landfald B (1997) High prevalence of polyunsaturated-fatty-acid producing bacteria in arctic invertebrates. FEMS Microbiol Lett 151:95-101

Kelly BJ (1997) Aspects of the chemistry and biology of Durvillaea antarctica and Durvillaea willana. PhD thesis, University of Otago, Dunedin

> Kelly JR, Scheibling RE (2012) Fatty acids as dietary tracers in benthic food webs. Mar Ecol Prog Ser 446:1-22

> Kelly JR, Scheibling RE, Iverson SJ, Gagnon P (2008) Fatty acid profiles in the gonads of the sea urchin Strongylocentrotus droebachiensis on natural algal diets. Mar Ecol Prog Ser 373:1-9

Kelly JR, Scheibling RE, Iverson SJ (2009) Fatty acids tracers for native and invasive macroalgae in an experimental food web. Mar Ecol Prog Ser 391:53-63
Layman CA, Araujo MS, Boucek R, Hammerschlag-Peyer $\mathrm{CM}$ and others (2012) Applying stable isotopes to examine food-web structure: an overview of analytical tools. Biol Rev Camb Philos Soc 87:545-562

- Marsden ID (1991a) Kelp-sandhopper interactions on a sand beach in New Zealand. I. Drift composition and distribution. J Exp Mar Biol Ecol 152:61-74

Marsden ID (1991b) Kelp-sandhopper interactions on a sand beach in New Zealand. II. Population dynamics of Talorchestia quoyana (Milne-Edwards). J Exp Mar Biol Ecol 152:75-90

McCutchan JH Jr, Lewis WM Jr, Kendall C, McGrath CC (2003) Variation in trophic shift for stable isotope ratios of carbon, nitrogen, and sulfur. Oikos 102:378-390

McLeod RJ, Wing SR (2007) Hagfish in the New Zealand fjords are supported by chemoautotrophy of forest carbon. Ecology 88:809-816

> McLeod RJ, Wing SR (2009) Strong pathways for incorporation of forest litter into a benthic marine food web. Estuar Coast Shelf Sci 82:645-653

Mellbrand K, Lavery PS, Hyndes GA, Hambäck PA (2011) Linking land and sea: different pathways for marine subsidies. Ecosystems 14:732-744

Nelson MM, Leighton DL, Phleger CF, Nichols PD (2002a) Comparison of growth and lipid composition in the green abalone, Haliotis fulgens, provided specific macroalgal diets. Comp Biochem Physiol B Biochem Mol Biol 131: 695-712

Nelson MM, Phleger CF, Nichols PD (2002b) Seasonal lipid composition in macroalgae of the northeastern Pacific Ocean. Bot Mar 45:58-65

> Nelson WA (1994) Distribution of macroalgae in New Zealand - an archipelago in space and time. Bot Mar 37: 221-233

Nichols DS (2003) Prokaryotes and the input of polyunsaturated fatty acids to the marine food web. FEMS Microbiol Lett 219:1-7

Parrish CC (2009) Essential fatty acids in aquatic food webs. In: Arts MT, Brett MT, Kainz M (eds) Lipids in aquatic ecosystems. Springer-Verlag, New York, NY, p 309-326

Peterson BJ (1999) Stable isotopes as tracers of organic matter input and transfer in benthic food webs: a review. Acta Oecol 20:479-487

Polis GA, Hurd SD (1996) Linking marine and terrestrial food webs: allochthonous input from the ocean supports high secondary productivity on small islands and coastal land communities. Am Nat 147:396-423

Schlechtriem C, Arts MT, Zellmer ID (2006) Effect of temperature on the fatty acid composition and temporal trajectories of fatty acids in fasting Daphnia pulex (Crustacea, Cladocera). Lipids 41:397-400

> Suring E, Wing SR (2009) Isotopic turnover rate and fractionation in multiple tissues of red rock lobster (Jasus edwardsii) and blue cod (Parapercis colias): consequences for ecological studies. J Exp Mar Biol Ecol 370:56-63

Tierney M, Nichols PD, Wheatley KE, Hindell MA (2008) Blood fatty acids indicate inter- and intra-annual variation in the diet of Adélie penguins: comparison with stomach content and stable isotope analysis. J Exp Mar Biol Ecol 367:65-74

Uki N, Sugiura M, Watanabe T (1986) Requirement of essential fatty acids in the abalone Haliotis discus hannai. Bull Jpn Soc Sci Fish 52:1013-1023

Wing SR, McLeod RJ, Clark KL, Frew RD (2008) Plasticity in the diet of two echinoderm species across an ecotone: microbial recycling of forest litter and bottom-up forcing of population structure. Mar Ecol Prog Ser 360:115-123 